\title{
The Impact of Tacit Knowledge Acquisition on Firm Performance: The Moderating Effect of Redundant Resources
}

\author{
Jing LIU, ${ }^{1}$ and Fei YU \\ Guilin University of Electronic Science and technology, China
}

\begin{abstract}
With the advent of knowledge economy, any enterprise can be regarded as providing "knowledge service" for customers. Through the process of tacit knowledge acquisition and innovation, enterprises will eventually transform tacit knowledge into the core competitiveness of enterprises. Based on the sample data of Chinese listed manufacturing companies for three consecutive years, this paper analyzes the impact of three ways of tacit knowledge acquisition (namely: employee training, research and development and market research) on enterprise performance, and introduces the factor of redundant resources to analyze its moderating effect on this relationship It is found that the three ways of tacit knowledge acquisition have significant positive effects on enterprise performance; different types of redundant resources (non precipitation redundant resources, precipitation redundant resources) strengthen and weaken the three positive relationship mechanisms. Based on the theory of resource-based view, it promotes the development process of knowledge acquisition and innovation under the knowledge economy of enterprises.
\end{abstract}

Keyword. Knowledge economy; tacit knowledge; acquisition method; redundant resources

\section{Introduction}

In 1999, with the rise of knowledge management theory research, many scholars at home and abroad began to invest in this field and published a series of articles. Effective knowledge management is an important way for enterprises to provide and continuously use knowledge to obtain competitive advantage [1]. Because tacit knowledge is implicit and difficult to imitate, it is not easy to be copied or stolen, and it is the source of enterprises to form core competitiveness. Compared with explicit knowledge, tacit knowledge can create more value, which is an important point in knowledge management [2].

How to obtain tacit knowledge from customers has become a hot topic in different industries and enterprises. The more secretive the knowledge is, the higher the value it brings, and enterprises will adopt a variety of technical methods to obtain tacit knowledge.

${ }^{1}$ Corresponding Author, Jing LIU, Guilin University of Electronic Science and technology, China; E-mail:1106749360@qq.com 
In addition, the acquisition of tacit knowledge is a resource consuming activity, especially for the tacit knowledge which is secret and difficult to manifest, it often needs the continuous resources; due to the uncertainty of the acquisition of tacit knowledge, some of the input resources may not bring any results to the enterprise. As an important "boost" of knowledge innovation, redundant resources are of great significance to tacit knowledge acquisition and innovation.

Many studies have found that tacit knowledge can bring high-value skills and experience, but now in this market with changeable demand, there are few quantitative studies on how to obtain tacit knowledge more effectively. Under the background of manufacturing industry, this paper analyzes three different ways of tacit knowledge acquisition, and explores the regulatory effect of redundant resources on each way of tacit knowledge acquisition.

\section{Theoretical basis and research hypothesis}

\subsection{Enterprise tacit knowledge acquisition and enterprise performance}

No matter the internal staff or the management, the external customers or the partners are the creators and storage of tacit knowledge. They are the origin of enterprise knowledge innovation. It is precisely because of the fluidity of knowledge that enterprises rely on the process of knowledge flow and transformation to realize knowledge innovation."Flow" includes one-way and multi-directional flow between tacit knowledge subjects. This process does not bring significant effect in tacit knowledge innovation, but it is a prerequisite for the process of tacit knowledge transformation.

Since the establishment of the enterprise, the knowledge flow and transformation of the enterprise is a continuous cycle process. The research and analysis of the "flow" of enterprise tacit knowledge has a certain impact on the successful "transformation" process, and the tacit knowledge innovation effect brought by the flow of different tacit knowledge carriers is different. It is necessary to grasp and analyze the complex relationship and law of the flow process.

Enterprises use the "flowing" tacit knowledge to improve their core competitiveness, so as to improve their performance [2]; secondly, enterprises have diversified tacit knowledge, which is conducive to enterprises to adapt to the dynamic environment, so as to make enterprises realize sustainable development; thirdly, after acquiring tacit knowledge, the main staff of enterprise goal implementation can improve their work efficiency and stimulate their knowledge innovation ability. Lu Xin et al. believe that tacit knowledge acquisition level has a positive impact on core competitiveness, clearly pointing out that the core competitiveness of enterprises has a positive relationship with the tacit knowledge acquisition level[3].Therefore, this paper believes that enterprise acquires tacit knowledge is beneficial to enterprise performance.

H1: tacit knowledge acquisition has a positive impact on firm performance.

Ren Zhijuan believes that the knowledge-based enterprise capability theory holds that the competitive advantage of enterprises does not come from knowledge itself, but from the acquisition and management of knowledge[4].According to Zhang Qingpu, tacit knowledge is distributed among employees, teams, departments, enterprises and other knowledge subjects at different levels [5].In the process of tacit knowledge flow, 
tacit knowledge is generated by the self-renewal and mutual collision of these knowledge subjects. Starting from different knowledge subjects, there are different ways to acquire tacit knowledge.

Firstly, the tacit knowledge produced by individual employees. Employees have intuition, inspiration, observation, beliefs and other characteristics, which will produce tacit knowledge beyond the technical equipment, and can better meet the diverse needs of consumers. Through staff training and staff recruitment, new tacit knowledge can be brought to enterprises.

Due to the deeper understanding of the enterprise's products, and customers, the employees will produce a lot of tacit knowledge from their years of experience. If the enterprise trains them and grants them the right to learn skills, the employees will improve themselves in all aspects and summarize more innovative tacit knowledge; the formation of tacit knowledge will be accelerated. In addition, Lu Xin et al. believe that tacit knowledge acquisition of high-tech enterprises has a positive effect on organizational learning[5].

Second, tacit knowledge generated by groups (teams, departments).In a group, each knowledge individual has an environment of close interaction and direct communication. Through comprehension, absorption and transformation, tacit knowledge that can understand each other but can not be explained. Through the establishment of formal project development groups, as well as informal groups such as interest groups and communities.

Nowadays, more and more enterprises have set up R \& D teams for a certain research project. The team members are slightly better than ordinary employees in terms of educational and work background. They have the skills of summarizing, transforming, analyzing and innovating knowledge. High-level personnel gather together and carry out ideological exchange, which can produce more tacit knowledge. Besides the satisfaction of soft resources, the R \& D of marketable new products and services also requires the supply of hard resources such as technology and equipment.

Third, tacit knowledge produced by enterprises. This level can be divided into two different levels: The one is the tacit knowledge generated by the enterprise itself. In this stage, it requires continuous long-term integration and practice. The second is the tacit knowledge produced by the enterprise and other enterprises. With the help of "external brain", the enterprise introduces a variety of technical know-how and skills to exchange knowledge, and finally transforms the tacit knowledge into ones which is be mastered .This level can establish a wide range of knowledge alliances with customers, suppliers, universities, research institutions and even competitors[6].

In the past, in the process of independent $\mathrm{R} \& \mathrm{D}$, the researchers of the enterprise only considered the design and development according to the product performance, aesthetics and other aspects, and purchased by customers. Now, if an enterprise wants to develop a successful new product, it must first have an in-depth understanding of customers' needs, which allows customers to participate in the development process of new products. In the process of two-way communication, after obtaining a large number of customer information needs, the enterprise finally splits the information knowledge, restructures and integrates new products. Therefore, we can think that after enterprises deepen the connection with the market and obtain a large amount of tacit knowledge from customers, they will promote enterprises to produce tacit knowledge related to new product development [7].

$\mathrm{H}$ 2: there are significant differences in the impact of different ways of tacit knowledge acquisition on enterprise performance. 


\subsection{Regulatory role of redundant resources}

.Bourgeios Redundant resources are defined as the actual or potential idle resources in the organization, which can help the enterprise to cope with the pressure caused by internal and external changes[8].Sufficient resources enable enterprises to selectively take actions to adapt to environmental changes, and provide support for the plans and projects , so as to improve enterprise performance. In all kinds of innovation activities, enterprises need to consume resources, and the innovation activity itself has great uncertainty. Even if enterprises have more redundant resources, it is difficult to meet all the resources required by innovation activities, and it is affected by the utilization efficiency of redundant resources.[8][9]

The literature in the field of tacit knowledge acquisition and innovation is less concerned with the regulatory role of redundant resources. Different types of resources combined with different ways of tacit knowledge acquisition will eventually produce different degrees of effect. According to the liquidity and flexibility of assets, redundant resources can be divided into two types: non precipitation and precipitation redundant resources. Therefore, this paper considers the different moderating effects of these two different resources on the relationship.[10]

(1) Regulatory role of non precipitation redundant resources

Non precipitation redundancy refers to the resources with high liquidity and flexibility that are not designated for a specific purpose, including cash, reserve funds, etc., which can be temporarily transferred. In addition, this resources are easy to obtain, transfer and redistribute within the enterprise, and the consume fast. Due to the its traits, enterprise managers have greater autonomy on the resources, and even lead to more ineffective consumption. As a result, the education funds invested by enterprises for staff training actually become unprofitable management costs, such as the travel expenses and high training facilities reserve expenses, etc. Besides, employees are more likely to become dependent on this resource, and ignore their own non resource aspects of tacit knowledge creation skills. Therefore, we make conclude the following hypothesis:

H3: non precipitated redundant resources negatively regulate the relationship through employee training and improving enterprise performance.

Non precipitation redundancy is often used to help enterprises engage in new strategies, such as new product introduction and entering new markets. Because the allocation of this resource is easy to be unconstrained, enterprises can acquire new knowledge in a short time by investing them in new market development [11].Therefore, we can make the following hypothesis:

H4: non precipitated redundant resources positively regulate the relationship through market development and improving enterprise performance.

When facing new opportunities in the field of technology, managers of innovative enterprises can invest resources in time, through their own knowledge reserve and absorption and transformation ability of $\mathrm{R} \& \mathrm{D}$ personnel. Therefore, it can be concluded that: in the process of $\mathrm{R} \& \mathrm{D}$, the use of non precipitation redundant resources can promote the acquisition of tacit knowledge, so as to achieve the improvement of enterprise performance.

H5: non precipitated redundant resources negatively regulate the relationship between enterprises acquiring tacit knowledge through $\mathrm{R} \& \mathrm{D}$ and improving enterprise performance. 
(2) Regulatory role of precipitable redundant resources

Compared with non precipitation redundant resources, precipitation redundant resources have poor mobility and flexibility, which can only be directly applied to special situations. The use of precipitation redundant resources with poor flexibility will limit the method of generating new tacit knowledge, and employees cannot quickly and effectively allocate resources to the path that is conducive to their own acquisition, absorption and transformation of tacit knowledge, thus reducing the efficiency of tacit knowledge generated in employee training.

H6: precipitated redundant resources negatively regulate the relationship between tacit knowledge acquired through employee training and enterprise performance.

Because of its poor liquidity and flexibility, enterprises with more redundant resources are difficult to cope with the rapid changes of the external market. Facing the tacit knowledge of customers in the new market, managers can not respond in time and it is difficult to innovate enterprise tacit knowledge.

H7: precipitation of redundant resources negatively regulates the relationship between tacit knowledge acquired through market development and enterprise performance.

The characteristics of low liquidity can sometimes provide stable and lasting help for enterprises. Compared with the non-precipitation redundant resources, the greater the liquidity is, the re-transfer and redistribution within the enterprise will lead to poor stability. In addition, the use of the stable resources can reduce the risk of enterprise $\mathrm{R}$ $\&$ D projects, ensure the smooth progress of work, and further realize the purpose of obtaining tacit knowledge.

H8: precipitating redundant resources negatively regulates the relationship between enterprises acquiring tacit knowledge through R\&D and improving enterprise performance.

\section{Research design}

\subsection{Data collection}

Due to the incomplete data of the database in 2019, this paper selects the Chinese listed manufacturing industry( the industry classification of China Securities Regulatory Commission (CSRC) 2012 edition is used as the sample object) from 2016 to 2018 as the research sample, a total of 2161 enterprises, eliminating the companies with incomplete financial data and * ST companies(A company with two consecutive years of special treatment for its losses), and finally obtains 50 effective enterprise samples. The original data are all from Chinese CSMAR database.

\subsection{Variable measurement}

The variable indexes involved in this paper come from the public notes to financial statements of Chinese listed companies. We use panel data to analyze the enterprises in different industries. Moreover, the relevant indicators are as follows.

(1) Dependent variable: This paper uses operating income to measure enterprise performance.

(2) Independent variable: The independent variables of this study are as follows: 
Employee training: it mainly refers to the capital strength invested by the enterprise in the ability training and technical training of internal employees.

Research and development $(\mathrm{R} \& \mathrm{D})$ : refers to the financial support required by the enterprise R \& D team to develop new products and services.

Market Research: the independent variable can be measured by the cost of all kinds of enterprises' involvement in the market.

(3) Regulatory variables: The regulating variable of this paper is redundant resources. Referring to Herold's measurement method, non precipitation resources are measured by dividing current assets by current liabilities. The precipitated redundant resources are measured by the owner's equity divided by the total liabilities formula.[12]

(4) Control variables

In order to ensure the normal distribution of data, this paper will use these three variables as control variables: enterprise size; enterprise age; industry.

\section{Result analysis}

\subsection{Descriptive statistics and correlation coefficient analysis}

By using the Eviews software can show the descriptive statistical results and correlation coefficient statistical results among the variables. And the control variables are significantly correlated with independent variables and dependent variables, which indicates that it is necessary to control the control variables. By calculating the variance inflation factor, it was found that the VIF values among all variables were all lower than 2 , far less than the critical value of 10 . Therefore, the problem of multicollinearity in the data of this sample was not serious.

Table 1 shows the results of multiple linear regression. Model 1 is a benchmark model with only control variables. In model 2, model 4 and Model 6, three independent variables were respectively added on the basis of the benchmark model, and their regression coefficients were significantly positive. The results show that the input cost of employee training, the input cost of market research and the input cost of R \& D have different significant positive effects on enterprise performance, so hypothesis 1 and hypothesis 2 are verified.

In model 3, the variables of interaction between staff training and SR1, SR2 are added on the basis of the benchmark model, and the regression coefficient of employee training cost and two kinds of redundant resource interaction items is significantly negative, It shows that the use of these two redundant resources will weaken the positive relationship between tacit knowledge and enterprise performance. Hypothesis 3 and 6 are verified. In Model 5, hypothesis 4 can be verified by using the same analysis method in the previous paragraph; while the hypothesis 7 can not pass the test. In Model 7, hypothesis 5 can be verified; while the hypothesis 8 can not pass the test. 
Table 1 multiple regression model of tacit knowledge acquisition mode on Enterprise Performance

\begin{tabular}{|c|c|c|c|c|c|c|c|}
\hline Independent variable & Model 1 & Model 2 & Model 3 & Model 4 & Model 5 & Model 6 & Model 7 \\
\hline Staff training & & $0.070315^{* * * *}$ & 0.061843 & & & & \\
\hline Marketing research & & & & $0.313445^{* * * * *}$ & $0.360398 * * * *$ & & \\
\hline$R \& D$ & & & & & & $0.078946^{* * *}$ & $0.168493^{* *}$ \\
\hline Staff trainingxSR1 & & & $-0.154813^{*}$ & & & & \\
\hline Staff trainingxSR2 & & & $-0.179038^{* * * *}$ & & & & \\
\hline Marketing researchxSR1 & & & & & $0.130779^{*}$ & & \\
\hline Marketing researchxSR2 & & & & & -0.068587 & & \\
\hline R\&D xSR 1 & & & & & & & $0.144344^{*}$ \\
\hline R\&D xSR2 & & & & & & & 0.021524 \\
\hline
\end{tabular}

\section{Research deficiencies and prospects}

There are three limitations in this study: (1)Due to the limitation of selecting three independent variables at the same time for three consecutive years, only 50 enterprises are selected to meet the research purpose. Therefore, the follow-up study can consider using other indicators to measure the research object.(2) This research is an independent analysis and research through three levels of tacit knowledge subject, but does not research on enterprises taking a variety of tacit knowledge acquisition methods at the same time. In general, most enterprises can acquire tacit knowledge and innovate only in one way. Therefore, the follow-up research needs to deeply explore the interaction of different ways.(3) In this paper, the moderating effect of precipitation redundant resources is only considered for the three-year relationship between dependent variables and independent variables. In fact, the moderating effect of precipitation redundant resources may take a long time to reflect, and the lag data can be used for regression analysis.

\section{Reference}

[1] Martins V W B, Rampass I S, Anholon R, et al. Knowledge management in the context of sustainability: literature review and opportunities for future research [J].Journal of Cleaner Production, 2019,229: 489-500.

[2] Yuan Qinghong, J enterprise intellectual capital management [M]. Beijing: economic management press, 2001.87-98

[3] Lu Xin, Song Zaixun, Huang Jieyu.Research on the relationship between tacit knowledge acquisition level and core competence of high-tech enterprises [J]. Journal of Peking University of China (Social Science Edition),2019,35(06):108-114.

[4] Ren Zhijuan. Research on the relationship between tacit knowledge acquisition, knowledge integration ability and firm innovation performance [D].Zhejiang Normal University,2018.

[5] Zhang Qingpu, Li Zhichao. Characteristics and management of enterprise tacit knowledge [J]. Economic theory and economic management, 2002 (11): 47-50

[6] Lu Xin, Huang Jieyu, Zhao Yun.Research on the influence of innovation climate on innovation performance in high-tech enterprises: the dual mediating role of implicit knowledge acquisition and organizational learning [J].Technological Economics and Management Research,2020(08):49-53.

[7] Brown S L, Eisenhardt K M. Product development:Past research, present findings, and future directions[J].Academy of Management Review, 1995,20(2):343-378.

[8] Bourgeois, L.J. On the measurement of organizational slack [J]. Academy of management Review, 1981, 6 (1): 29- 39 
[9] Sun Aiying, Su Zhongfeng. Research on the influence of resource redundancy on the choice of enterprise technological innovation [J]. Science of science and technology management, 2008 (05): $60-63+68$

[10] Jiang Weiping, Liu Daidi. Research on the relationship between R \& D investment, redundant resources and enterprise performance [J]. Financial theory and practice, 2016,37 (05): 57-62

[11] Zhang Qinglei, Shi Jianjun, Liu Chunlin. Research on the relationship between technological diversification, redundant resources and enterprise performance [J]. Scientific research management, 2015,36 (11): 21-28

[12] Herold, D. M., Jayaraman, N., Narayanaswamy, C. R.. What Is the Relationship between Organizational Slack and Innovation?[J].Journal of Managerial Issues, 2006, 18(3): 372-392. 